\title{
Frequency Selective Surface Properties of Microwave New Absorbing Porous Carbon Materials Embedded in Epoxy Resin
}

\author{
Diego Edissón Flórez Vergara ${ }^{a}$, Braulio Haruo Kondo Lopes ${ }^{a}$, Sandro Fonseca Quirino ${ }^{b}$, \\ Guilherme Frederico Bernardo Lenz e Silvac, Alan Fernando Ney Boss', Gisele Aparecida \\ Amaral-Labat $*$ (1), Mauricio Ribeiro Baldan ${ }^{a}$
}

\author{
${ }^{a}$ Laboratório Associado de Sensores e Materiais - LABAS, Instituto Nacional de Pesquisas Espaciais - INPE, \\ São José dos Campos, SP, Brasil \\ ${ }^{b}$ ETEP Faculdades, São José dos Campos, SP, Brasil \\ ${ }^{c}$ Departamento de Engenharia Metalúrgica e de Materiais - PMT, Universidade de São Paulo - USP, \\ São Paulo, SP, Brasil
}

Received: December 08, 2018; Revised: July 02, 2019; Accepted: August 15, 2019

\begin{abstract}
In this manuscript, the electromagnetic wave absorption properties of sustainable porous carbon composites were evaluated over the $\mathrm{X}$-band frequency range $(8.2-12.4 \mathrm{GHz})$. The porous carbon material was made from the byproduct of cellulose production and was used as additive on the development of radar absorbing material (RAM) composites. These porous carbon materials have different characteristics, such as porosity size $\left(180 \mu \mathrm{m}<\varnothing_{1}<250 \mu \mathrm{m}\right.$ and $\left.425 \mu \mathrm{m}<\varnothing_{2}<500 \mu \mathrm{m}\right)$ and particle size $\left(\phi_{1}<250 \mu \mathrm{m}\right.$ and $\left.250 \mu \mathrm{m}<\phi_{2}<425 \mu \mathrm{m}\right)$. Composite materials were also studied as frequency selective surface (FSS) structures. It was shown how complex permittivity and reflection loss (RL) can be manipulated over the frequency range using FSS structure. While regular RAM presented RL of $19 \mathrm{~dB}$ at $\sim 11.8 \mathrm{GHz}$, FSS structure presented a RL of $19 \mathrm{~dB}$ shifted to $12.4 \mathrm{GHz}$ regarding the same carbon porous material (with particles between 250 and $425 \mu \mathrm{m}$ and porosity between 180 and $250 \mu \mathrm{m}$ ). It was demonstrated here the potential use of sustainable porous carbon as RAM, and how FSS structure can be used to tune the frequency of the RL maximum peak.
\end{abstract}

Keywords: Frequency selective surface, radar absorbing material, porous carbon, composite materials.

\section{Introduction}

The technological advances on wireless technologies created an exponential growth on the usage of radio and microwave frequencies, enhancing undesired interferences on electronic devices ${ }^{1-3}$. Also, as far as radio and microwave frequencies are nonionizing, there are studies about their effects on human health, since they are suspected to collaborated on cancer, cardiovascular disease, cataract and reproductive complications ${ }^{4}$. Even with no conclusive results about the harmfulness on human health, it has been already proved that electromagnetic interference (EMI) has negative effects on implantable devices and life support equipment, which is why there is an European regulation for a $10 \mathrm{~m}$ distance between electromagnetic radiation sources and life support equipment on medical environments ${ }^{5}$.

Currently, there are regulations limiting electromagnetic emissions on equipment and environments ${ }^{6}$, which can be achieved through electromagnetic shielding using metal or radar absorption material (RAM) $)^{7,8}$. Although metallic structures may have advantages because of its broadband electromagnetic shielding, RAM has the advantage of being lightweight, corrosion resistant and flexible? .
That's because RAM are composites made with polymeric matrix (e.g. silicone rubber or epoxy resin) and a lossy filler (e.g. carbon black or ferrite). In this sense, several researchers seek the development of a broadband highly efficiency RAM.

EMI shielding date back to 1830's when Michael Faraday first produced the Faraday cage, but the use of carbon for EMI shielding came only a hundred years later. During World War II, it was demonstrated the capability of RAM for military uses, which engaged a technological competition on material design to improve RAM efficiency. Stealth technology was raised from that effort, generating different technologies and materials to avoid radar detection. Perhaps, the most noticeable stealth aircrafts are the F-117 Nighthawk and the B-2 Spirit, which combines geometry with RAM to reduce their radar cross section. However, it is interesting to notice that carbon has always been considered on the RAM development. It was in the 1940's that carbon black was first being submitted to RAM studies, and in the 1960's there were already carbon coating. In the 1980 's, attention was directed to the use of carbon fibers, followed by carbon nanotubes in the 2000's and graphene in the 2010 's ${ }^{10,11}$. 
Using carbon nanotubes and graphene on RAM materials have the disadvantage of high costs and time-consuming production. Also, using these materials as fillers provide a high permittivity and a low permeability, causing a high impedance mismatch. This has a direct impact on the reflection loss (RL), which is the parameter used to describe how much a RAM can absorb the electromagnetic wave9. However, there is a third type of carbon that has being vastly explored lately: the porous carbon material. Porous carbon has advantages over carbon nanotubes and graphenes, such as low costs and easy manufacturing. Also, porous carbon finds advantages on RAM technologies, even when its porosity is smaller than wavelength. That's because porosity helps on the weight and permittivity controlling of the filler, once a porous carbon material with porosity smaller than the wavelength maybe considered as a dielectric material with a medium permittivity averaged by the amount of carbon and air. Another advantage is that porous carbon can be produced from sustainable sources like coconut shell or black liquor (a byproduct of cellulose manufacturing), helping on the development of sustainable novel devices ${ }^{12-14}$.

The permittivity of porous carbon may be controlled by porosity ${ }^{13}$, but the lack of magnetic properties still has effects on impedance mismatching and RL. This issue can be overcome through material geometry manipulation, such as frequency selective surface (FSS). Usually, FSS is a two-dimensional periodic metallic array element on a dielectric substrate. The incident wave can be partially, or completely, transmitted or reflected, depending on the frequency matching between the incident wave and FSS resonance frequency. The ability of FSS to interact with electromagnetic waves is strongly related to its geometry, size and periodicity, as well as with the substrate electrical properties. Early in the 1970 's, Chen ${ }^{15}$ theoretically described the effects of thickness and resonant shifts based on the incident wave angle on a metallic plate. His work supplied theoretical information on a growing topic back in the days. Since then, FSS structures have evolved to more complex sizes, geometries and frequencies ranges. Nowadays, it finds applications on wireless communications, electromagnetic compatibility (EMC)/EMI, lenses for antennas, controlling of radar crosssection, and so on ${ }^{16-24}$.

FSS structures can also be made with carbon materials, where applications range from aerospace to electronic devices $^{25,26}$. FSS using carbon has an advantage on being easily modified along with their properties ${ }^{27}$. Therefore, this paper aims on the development of RAM using porous carbon material as filler, providing information of how permittivity can be controlled with porous carbon material and illustrating how FSS structure can be applied to tune $\mathrm{RL}$ over the X-band frequency range.

\section{Experimental}

\subsection{Porous carbon synthesis}

The byproduct of cellulose production, i.e. black liquor, was used as a precursor for sustainable porous carbon. Porosity was added as follow: the black liquor was first mixed with formaldehyde and then with resorcinol. Then spherical polymethacrylate (PMMA) in two different diameters (180 $\mu \mathrm{m}<\varnothing_{1}<250 \mu \mathrm{m}$ and $425 \mu \mathrm{m}<\varnothing_{2}<500 \mu \mathrm{m}$ ) was added separately, making sustainable porous carbons with two different porosities. Table 1 describes the order that each component was added, as well as their mass proportions. Components were sequentially added while the aqueous solution was stirring with an average velocity and temperature of $20 \mathrm{rpm}$ and $35^{\circ} \mathrm{C}$, respectively. This process took around 30 minutes with a magnetic stirrer, where solution viscosity gradually increased until it becomes a solid gel. The solid gel was left for curing during three days at room temperature. After the material was submitted to a carbonization process in a horizontal furnace (EDG $10 \mathrm{P}-\mathrm{S}$ ) at $900{ }^{\circ} \mathrm{C}$ under inert argon atmosphere and washed to remove inorganic salts coming from black liquor waste. The final product is a sustainable porous carbon with two different pores sizes, which were defined by PMMA spheres.

Table 1. Porous carbon compositions ordered by addition.

\begin{tabular}{|c|c|c|c|}
\hline Order & & Component & Mass $[\mathrm{kg}]$ \\
\hline 1 & & Black liquor & 0.100 \\
\hline 2 & & Formaldehyde & 0.044 \\
\hline 3 & & Resorcinol & 0.015 \\
\hline 4 & PMMA & $\begin{array}{l}180 \mu \mathrm{m}<\varnothing_{1}<250 \mu \mathrm{m} \\
425 \mu \mathrm{m}<\varnothing_{2}<500 \mu \mathrm{m}\end{array}$ & 0.045 \\
\hline
\end{tabular}

The material processing provided a first material classification based on the desired porosities according to PMMA spheres sizes. A second material classification intends to preserve the porosity created with PMMA spheres by choosing two different particles sizes after grinding, aiding on the formation of porosity patterns in different particle size. This is done by sifting porous carbon using two sieves with mesh sizes of $250 \mu \mathrm{m}$ and $425 \mu \mathrm{m}$. So, the first material group is composed of particles that went through $425 \mu \mathrm{m}$ sieve and remained in the $250 \mu \mathrm{m}$ sieve $\left(250 \mu \mathrm{m}<\phi_{2}<425 \mu \mathrm{m}\right)$, and the second group is composed by particles that went through both sieves, resulting in particles smaller than $250 \mu \mathrm{m}\left(\phi_{1}<250 \mu \mathrm{m}\right)$. The main classification is based on possible combinations of porosity and particle size, resulting in a total of four different porous carbon that were used as additive (Table 2). 
Table 2. Classification based on particle size and porosity.

\begin{tabular}{ccc}
\hline Combination & Particle size $[\mu \mathrm{m}]$ & Porosity size $[\mu \mathrm{m}]$ \\
\hline $\mathrm{C} 1$ & $\phi_{1}<250$ & $180<\emptyset_{1}<250$ \\
$\mathrm{C} 2$ & $\phi_{1}<250$ & $425<\emptyset_{2}<500$ \\
$\mathrm{C} 3$ & $250<\phi_{2}<425$ & $180<\emptyset_{1}<250$ \\
$\mathrm{C} 4$ & $250<\phi_{2}<425$ & $425<\emptyset_{2}<500$ \\
\hline
\end{tabular}

\subsection{Porous carbon / epoxy resin composites}

Composite material samples were prepared through manual mixing, where three different proportions $(5 \mathrm{wt} \%$, $10 \mathrm{wt} \%$ and $15 \mathrm{wt} \%$ ) of porous carbon were used on epoxy resin. The epoxy resin matrix used was LR $200 \mathrm{~F}$ - ABCOL. Composite samples dimensions were based on Keysight WR90 X11644A calibration kit, which specifies width and length of devices under test (DUTs). The sample thickness was stablished as $2.0 \mathrm{~mm}$ for all composites for comparison purpose. After previous characterization, composite samples were transformed into frequency selective surface (FSS) structures through mechanical drilling, where the first set of FSS had two equidistant holes of $2.0 \mathrm{~mm}$ diameter and the second set had two equidistant holes of $5.0 \mathrm{~mm}$ diameter. Both perforations were separated by $11.5 \mathrm{~mm}$ between centers. Figure 1 illustrates the geometric models of each composite sample submitted to EM characterization.

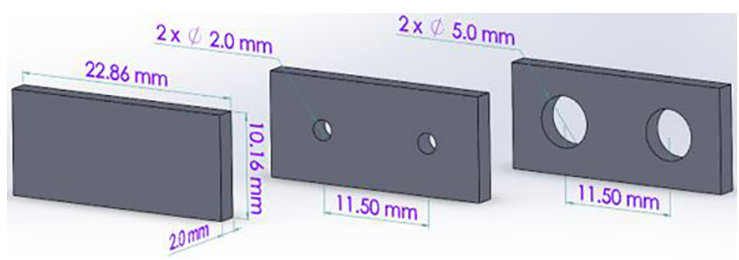

Figure 1. Dimensions of regular sample and FSS structures.

\subsection{Characterizations and measurements}

Structural analysis and phase composition of porous carbon were performed with a X-Ray Diffraction (XRD, Xpert PRO MPD Multi-Purpose Diffractometer) equipped with a monochromatized $\mathrm{Cu}-\mathrm{K} \alpha$ radiation. The scanning range of $2 \theta$ ranged from $10^{\circ}$ to $70^{\circ}$, with steps of $0.02^{\circ}$, spinning equals 2 and time per step of $10 \mathrm{~s}$. Porous carbon morphology and porosity were also observed with a Scanning Electron Microscopy (SEM, TESCAN VEGA 3) and a mercury porosimeter (Autopore III - 9400 micromeritics) variating the pressure from 1.59 to 60000 psia. Electromagnetic measurements were performed with a Vector Network Analyzer (VNA, Agilent N5230C PNA-L) using a X-Band rectangular waveguide, which ranges from 8.2 to 12.4 GHz. VNA system was calibrated through transmission reflection line (TRL) method. VNA provides S-parameters data, which is the ratio of the reflected $\left(\mathrm{S}_{11}\right.$ and $\left.\mathrm{S}_{22}\right)$ or transmitted $\left(\mathrm{S}_{12}\right.$ and $\left.\mathrm{S}_{21}\right)$ waves by the incident wave.
Samples intrinsic parameters were calculated through Nicolson-Ross Weir (NRW) method ${ }^{28-30}$, which used S-parameters data to calculate the complex permittivity of samples $\left(\varepsilon^{*}=\varepsilon^{\prime}-\mathrm{j} \varepsilon^{\prime \prime}\right)$. Reflectivity is measured by placing a metallic plate behind the sample and plotted on a logarithmic scale.

\section{Results and Discussion}

\subsection{Porous carbon structure and morphology}

The diffractogram presented in Figure 2 shows a characteristic pattern for carbon structure, where both broaden peaks with intensities around 25 and 44 degrees corresponds to the atomic planes (002) and (101), respectively. Furthermore, peaks with smaller widths and lower intensities shows the presence of Chlorocalcite $\left(\mathrm{KCaCL}_{3} / 00-021-1170\right)$, a typical inorganic matter presented on biomass ashes ${ }^{31}$. Particle morphology and porosity are showed in Figure 3. Particle format follows an irregular pattern, where particles bigger than $250 \mu \mathrm{m}$ (Figures 3(a) and 3(b)) present a welldefined enclosed porosity structure, coming from PMMA spherical shape. On the other hand, particles smaller than $250 \mu \mathrm{m}$ (Figures 3(c) and 3(d)) have an almost undefined enclosed porosity structure and a significant increase in particle accumulation.

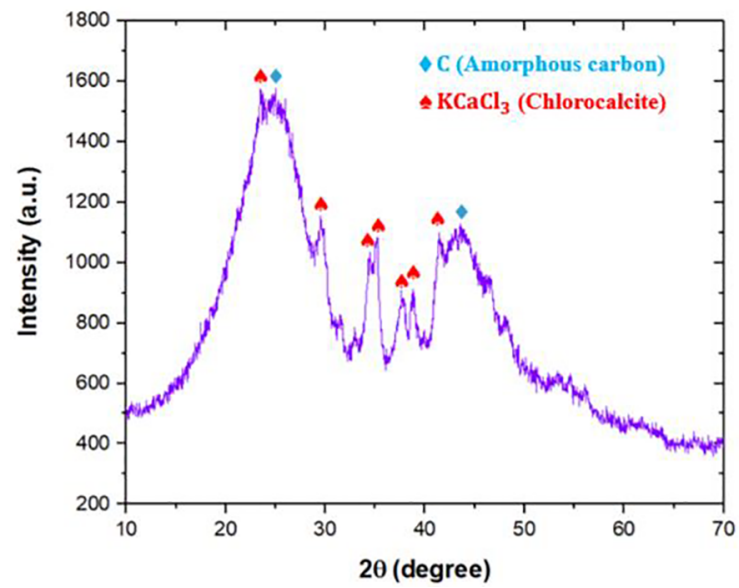

Figure 2. XRD spectrum of produced porous carbon material.

Pore size distributions of all samples, in a micrometric scale, were analyzed accordingly to mercury porosimetry results, as shown in Table 3. Despite the different PMMA particle size employed during the synthesis step, all porous carbon materials presented centered pores at $88 \mathrm{~mm}$, and only the $\mathrm{C} 1$ sample also presented centered pores at $6 \mathrm{~mm}$. Furthermore, the highest values of total pore area were 44 and $53 \mathrm{~m}^{2} / \mathrm{g}$ for C3 and $\mathrm{C} 4$, respectively. Samples $\mathrm{C} 1$ and $\mathrm{C} 2$ presented a smaller total pore area, possibly because of a porosity loss caused by the limited particle size $\left(\phi_{1}<250\right)$. However, $\mathrm{C} 1$ sample has a total pore area very close to $\mathrm{C} 3$ sample, which is possibly related to the additional pore areas centered at $6 \mu \mathrm{m}$. 

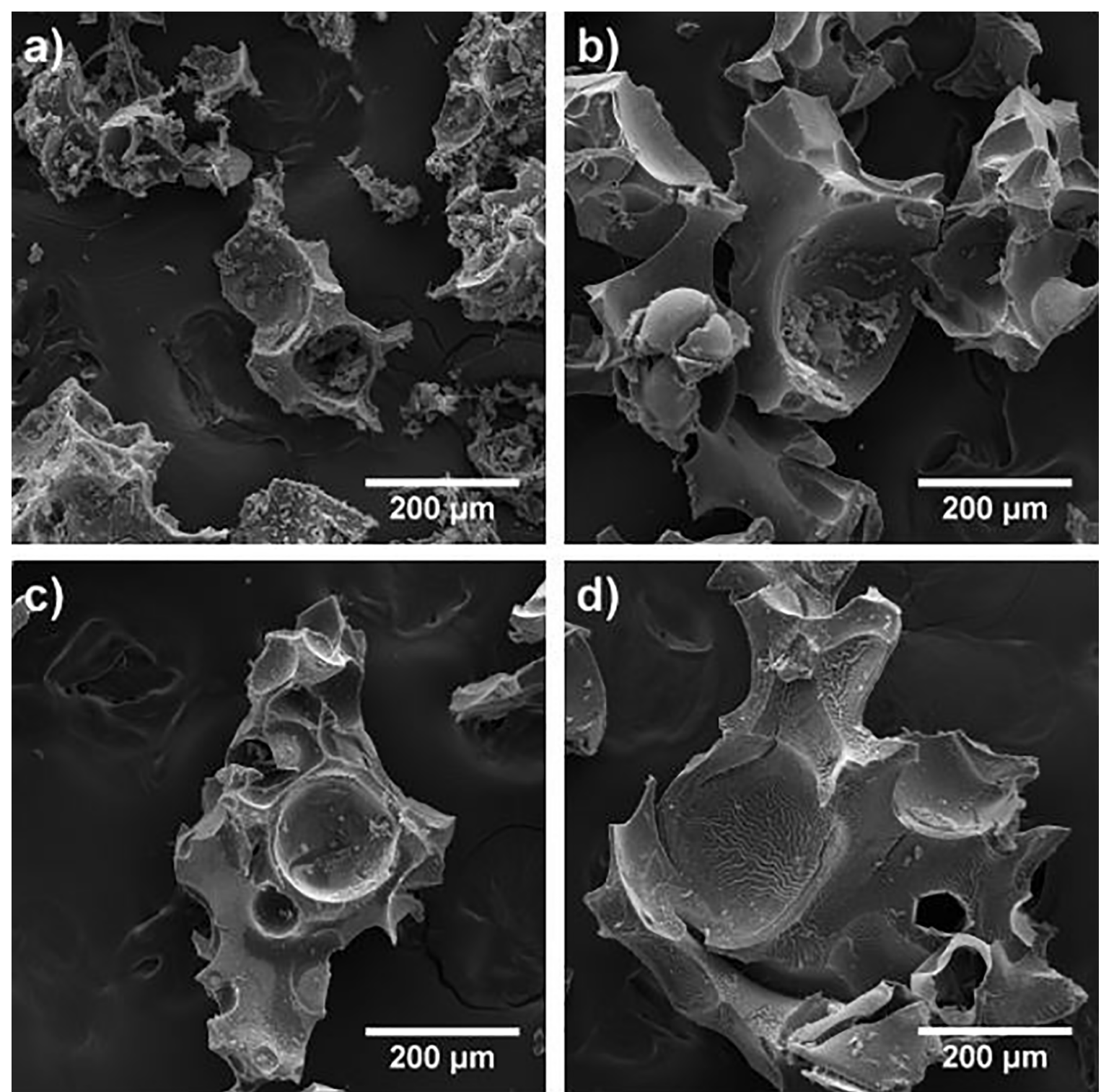

Figure 3. SEM images of porous carbon materials for particle size and porosity of a) C1, b) C2, c) C3 and d) C4.

Table 3. Porosity data from mercury porosimetry analysis.

\begin{tabular}{ccc}
\hline Combination & $\begin{array}{c}\text { Centered pore size distributions } \\
(\mu \mathrm{m})\end{array}$ & $\begin{array}{c}\text { Total pore area } \\
\left(\mathrm{m}^{2} / \mathrm{g}\right)\end{array}$ \\
\hline $\mathrm{C} 1$ & $88 ; 6$ & 41 \\
$\mathrm{C} 2$ & 88 & 20 \\
$\mathrm{C} 3$ & 88 & 44 \\
$\mathrm{C} 4$ & 88 & 53 \\
\hline
\end{tabular}

\subsection{Electromagnetic properties}

The complex permittivity of composite materials is given by real $\left(\varepsilon^{\prime}\right)$ and imaginary $\left(\varepsilon^{\prime \prime}\right)$ permittivities. These permittivities were calculated for all samples and are presented in Figure 4. As expected, permittivity increases with increasing carbon material concentration for all structures.
Complex permittivity for each sample without FSS can be observed in Figures 4(a) and 4(b), where values of capacitive and dissipative phenomena can be analyzed through real and imaginary permittivity, respectively. The best results were obtained for samples $\mathrm{C} 3$ and $\mathrm{C} 4$, where a greater particle size resulted in higher real permittivity. It is interesting to that real permittivity of $\mathrm{C} 4$ sample is higher than $\mathrm{C} 3$ samples when additive proportions are $5 \mathrm{wt} \%$ and $10 \mathrm{wt} \%$. However, real permittivity for $15 \mathrm{wt} \% \mathrm{C} 3$ sample is higher than $\mathrm{C} 4$ sample. Besides, the best dissipating energy response $(\mathrm{C} 4-15 \mathrm{wt} \%)$ is acquired with a greater particle size and porosity, besides the higher material concentration. This indicates that $\mathrm{C} 4$ sample is more conductive than $\mathrm{C} 3$ porous carbon.

Experimental analysis of FSS structure using rectangular waveguide has been reported before ${ }^{32,33}$. Since DUT is a periodic structure, rectangular waveguide measurements can be considered as an experimental simulation of a large 

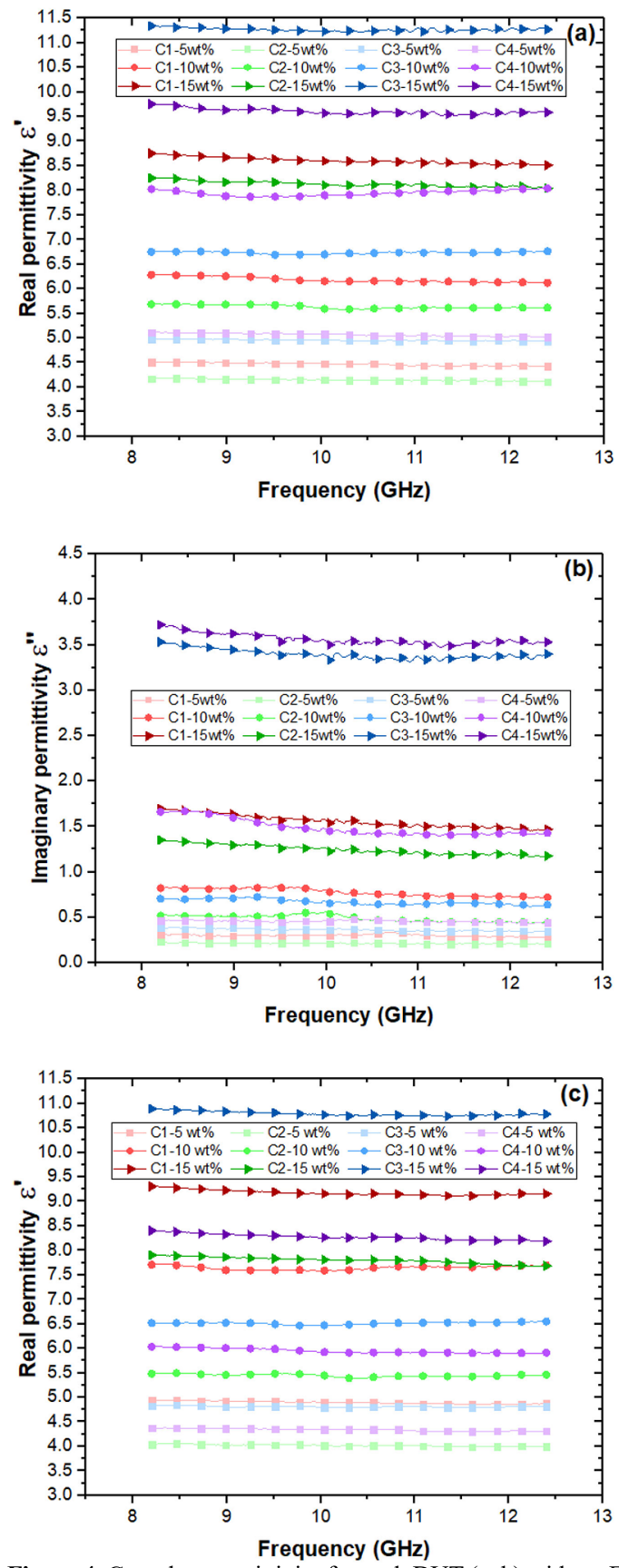

Figure 4. Complex permittivity for each DUT (a, b) without FSS, (c, d) with FSS of 2.0 mm diameter holes and (e, f) with FSS of 5.0 mm diameter holes.

FSS panel in free space. Thus, real and imaginary dielectric properties for the first set of DUTs with FSS structure $(2.0 \mathrm{~mm}$ diameter) are presented in Figures 4(c) and 4(d), respectively. The highest real permittivity value is also for sample using C3-15wt\%. However, the second highest permittivity value is for sample $\mathrm{C} 1-15 \mathrm{wt} \%$, while for composites without FSS is for $\mathrm{C} 4-15 \mathrm{wt} \%$. Since samples have the same material and are exclusively differentiated by the FSS geometry, the change of $\mathrm{C} 1$ results by $\mathrm{C} 4$ is a clear effect of FSS structure.
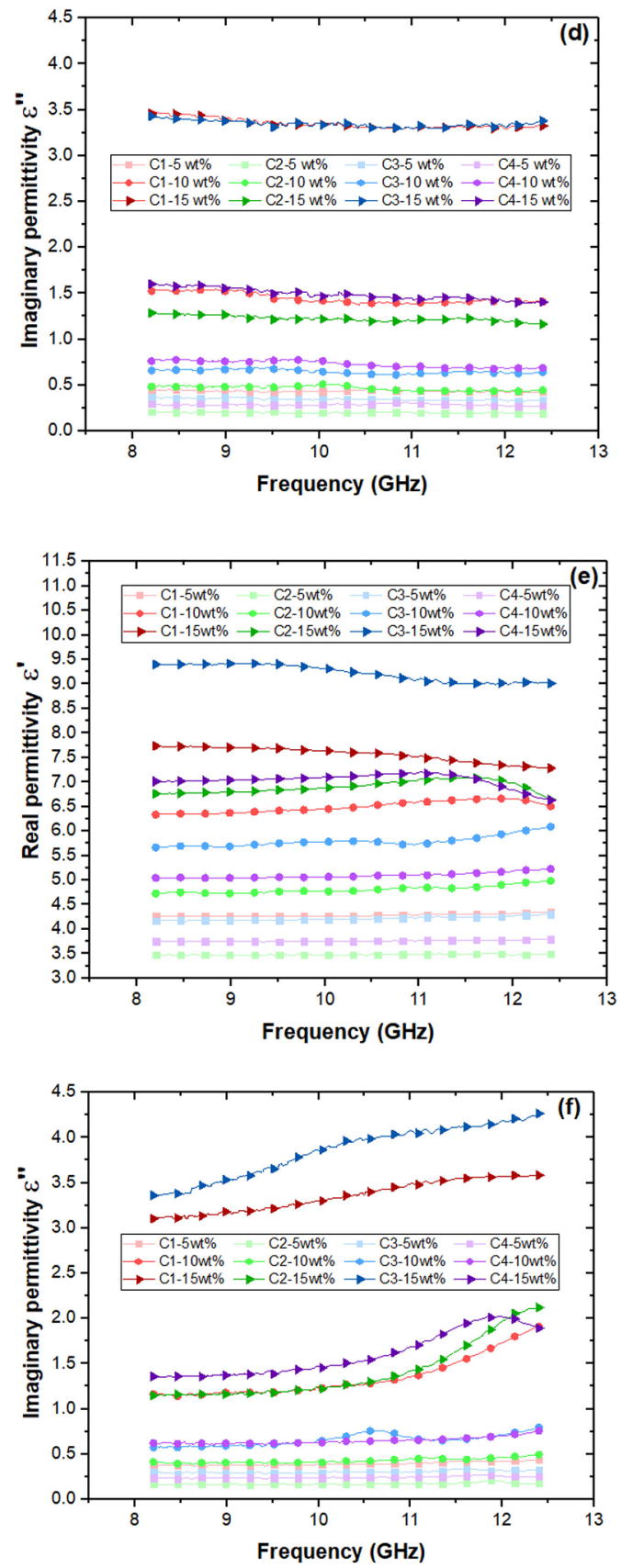

The imaginary permittivity of sample $\mathrm{C} 1$ (with $2.0 \mathrm{~mm}$ FSS and $10 \mathrm{wt} \%$ and $15 \mathrm{wt} \%$ ) were significantly increased, while for $\mathrm{C} 4$ samples were significantly decreased.

Lastly, the dielectric behavior for each DUT considering the second set of FSS structures ( $5.0 \mathrm{~mm}$ diameter) can be observed in Figures 4(e) and 4(f). This FSS structure also presented a change between $\mathrm{C} 1$ and $\mathrm{C} 4$ permittivity positions when compared to a sample with no FSS. However, this FSS presented a frequency dependence over the frequency range. 
It can be observed in Figure 4(e) a frequency dependence similarity behavior for all FSS samples with $15 \mathrm{wt} \%$. The sample with bigger permittivity (C3-15wt \%) has a difference about 1.8 for the second one (C1-15wt\%). Also, all DUTs with concentrations of $10 \mathrm{wt} \%$ and $15 \mathrm{wt} \%$ presented a nonlinearity above $10 \mathrm{GHz}$. In this FSS set, the highest imaginary permittivity values are for samples $\mathrm{C} 3$ and $\mathrm{C} 1$, as presented in Figure 4(f). The dissipating energy response for sample $\mathrm{C} 3-15 \mathrm{wt} \%$ is an effect of the bigger particle size, the higher material concentration and the smaller porosity combination. It is interesting to notice that imaginary permittivity values for samples with $15 \mathrm{wt} \%$ increases with increasing frequencies, a behavior that also happens for samples with $10 \mathrm{wt} \%$ carbon concentration. While a larger hole diameter reduced the real permittivity for sample $\mathrm{C} 3-15 \mathrm{wt} \%$, its imaginary permittivity increased for higher frequencies.

Summarizing, porosity and the particle size have direct influence on $\varepsilon^{\prime}$ and $\varepsilon^{\prime \prime}$ values, where higher values were obtained for porosity ranging $180 \mu \mathrm{m}<\varnothing_{1}<250 \mu \mathrm{m}$ and particle size ranging $250 \mu \mathrm{m}<\phi_{2}<425 \mu \mathrm{m}$. Figure 5 presents the dielectric properties of epoxy resin, where it can be notice that dielectric properties of composites can be tuned by choosing specific porosity and additive proportion. Also, electromagnetic properties of some samples can be manipulated by adding FSS geometries into the composite, improving their dispersive capacity at the same time it decreases their capacitive performance. Since sustainable porous carbon has been recently studied as RAM, there is no information in the literature about this material with FSS structure.

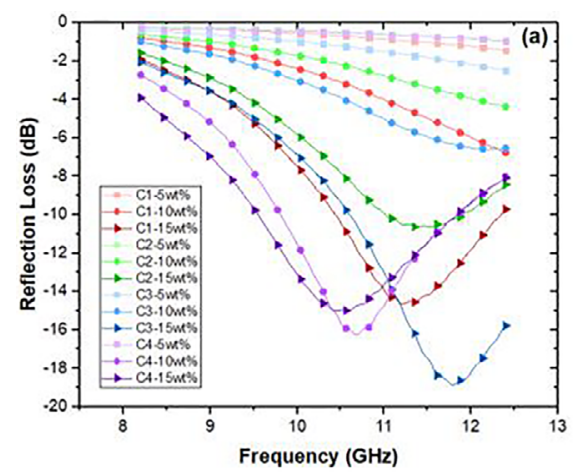

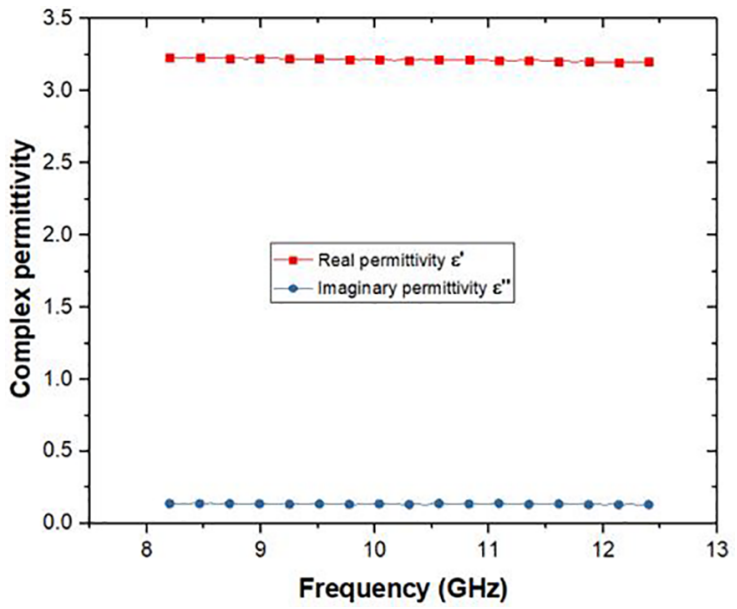

Figure 5. Complex permittivity of pure epoxy resin.

\subsection{Electromagnetic absorption evaluation}

EM absorption properties of composite materials were observed considering mass concentration, particle dimensions, porosity sizes and FSS structure. Figure 6 presents the reflection loss (RL) behavior for each DUT.

Figure 6(a) presents the RL for DUTs with no FSS structure. It is possible to notice a RL intensity about $-19 \mathrm{~dB}$ obtained for sample $\mathrm{C} 3-15 \mathrm{wt} \%$ at $\sim 11.7 \mathrm{GHz}$. This indicates that the best wave attenuation is associated with a greater particle size, higher material concentration and smaller porosity combination. There are other attenuation peaks below $-10 \mathrm{~dB}$, such as $\sim-16 \mathrm{~dB}$ for $\mathrm{C} 410 \mathrm{wt} \%, \sim-15 \mathrm{~dB}$ for

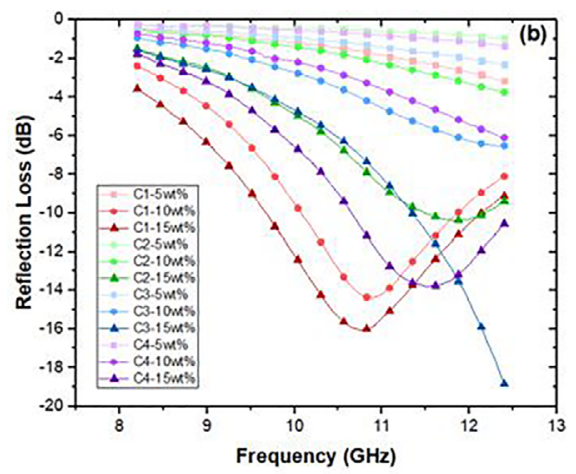

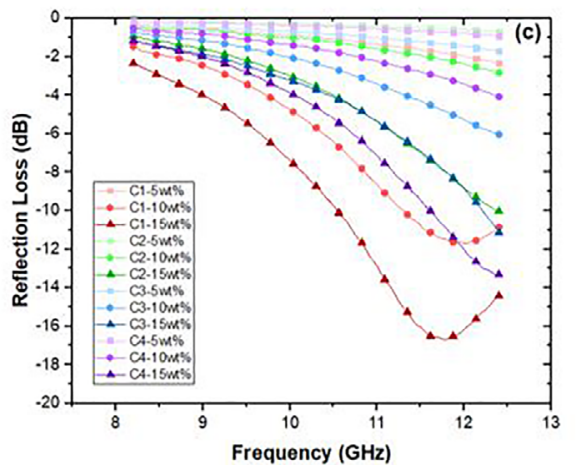

Figure 6. RL of DUT a) without FSS, b) with FSS of $2.0 \mathrm{~mm}$ diameter holes and c) with FSS of $5.0 \mathrm{~mm}$ diameter holes. 
C4-15wt $\%, \sim-14.5 \mathrm{~dB}$ for $\mathrm{C} 1-15 \mathrm{wt} \%$ and $\sim-10.5 \mathrm{~dB}$ for $\mathrm{C} 2-15 \mathrm{wt} \%$. All samples with $15 \mathrm{wt} \%$ proportion presented a RL lower than $-10 \mathrm{~dB}$, and only the $10 \mathrm{wt} \%$ proportion of $\mathrm{C} 4$ porous carbon presented a competitive RL when compared to those examples. As expected, higher additive concentration improves electromagnetic losses (imaginary permittivity), which justify the RL results, since all samples with a RL below $-10 \mathrm{~dB}$ have $\varepsilon^{\prime \prime}>1.25$.

The RL of DUT with $2.0 \mathrm{~mm}$ hole diameter FSS is presented in Figure 6(b). There is no significant variation on RL magnitudes when compared with Figure 6(a), excepted for sample $\mathrm{C} 1-10 \mathrm{wt} \%$ and $\mathrm{C} 4-10 \mathrm{wt} \%$, which now have $\sim-14.5 \mathrm{~dB}$ and $\sim-6.0 \mathrm{~dB}$, respectively. Again, this is justified by the imaginary permittivity greater than $\sim 1.25$ of those samples. It is also interesting to notice that all samples presented a frequency shift. C1-15wt $\%$ was shifted to lower frequencies, while $\mathrm{C} 2, \mathrm{C} 3$ and $\mathrm{C} 4$ samples with $15 \mathrm{wt} \%$ were shifted to higher frequencies.

Lastly, the second set of FSS structure $(5.0 \mathrm{~mm}$ diameter holes) had an even more outstanding rearrangement to higher frequencies, as observed in Figure 6(c). This is expected because geometry is a crucial parameter for FSS structures ${ }^{15}$. Since carbon porous material is a recent subject on RAM and FSS researches, there are no data in the literature to corroborate our results. This corroboration will be performed through EM computational simulation in further works, where it is expected a better understanding about the relation between porous carbon and FSS structure. However, since experimental simulations through the rectangular waveguide were positive, we believed that porous carbon material has potential application as RAM and FSS structure.

\section{Conclusion}

In summary, sustainable porous carbon was used as an additiveto develop RAM, which later was used as FSS structures. A detailed study about the influence of particle dimension, porosity size and carbon concentration on permittivity was performed. The results showed that composite materials made with sustainable porous carbon and epoxy resin have excellent properties as a RAM, which can be tuned through material concentration and porosity control. The best RL obtained with no FSS structure was $-19 \mathrm{~dB}$ for $\mathrm{C} 3-15 \mathrm{wt} \%$, which is about $99 \%$ of EM wave attenuation. Also, FSS structures were evaluated on RAM samples, where it was noticed a RL frequency shifting accordingly to diameter hole and imaginary permittivity. The best RL result for a $2.0 \mathrm{~mm}$ diameter hole is $-19 \mathrm{~dB}$ for $\mathrm{C} 3-15 \mathrm{wt} \%$, while for $5.0 \mathrm{~mm}$ diameter hole is $-17 \mathrm{~dB}$ for $\mathrm{C} 1-15 \mathrm{wt} \%$. Since application of porous carbon material as RAM is a new area of research, there is an information scarcity of FSS structures using this material. This lack of information is even scarcer considering an additive made of a byproduct of cellulose production.
However, electromagnetic measurements demonstrated that composite using epoxy and sustainable porous carbon is a strong candidate on the development of RAM composites. Experimental evaluations of FSS using rectangular waveguide presented the possibilities to manipulate RL through geometrical adjustment. Further works will be focused on computational simulation of FSS structure to provide corroboration to measured data.

\section{Acknowledgments}

This study has been supported by the National Institute of Space Research (INPE), University of São Paulo (USP) and CAPES.

\section{References}

1. van der Togt $R$, van Lieshout EJ, Hensbroek R, Beinat E, Binnekade M, Bakker PJM. Electromagnetic interference from radio frequency identification inducing potentially hazardous incidents in critical care medical equipment. Jama. 2008 Jun;299(24):2884-2890.

2. Shahparnia S, Ramahi O. Electromagnetic interference (EMI) reduction from printed circuit boards (PCB) using electromagnetic bandgap structures. IEEE Transactions on Electromagnetic Compatibility. 2004 Dec;46(4):580-587.

3. Li EP, Wei XC, Cangellaris AC, Liu EX, Zhang YJ, D'amore $\mathrm{M}$, et al. Progress review of electromagnetic compatibility analysis technologies for packages, printed circuit boards, and novel interconnects. IEEE Transactions on Electromagnetic Compatibility. 2010 May;52(2):248-265.

4. Ahlbom A, Green A, Kheifets L, Savitz D, Swerdlow A. Epidemiology of Health Effects of Radiofrequency Exposure. Environmental Health Perspectives. 2004 Dec;112(17):1741-1754.

5. Fernández-Chimeno M, Silva F. Mobile phones electromagnetic interference in medical environments: A review. In: Electromagnetic Compatibility (EMC). IEEE International Symposium on Electromagnetic Compatibility - 2010. Florida: IEEE; 2010. p. 311-316.

6. Lakshmi RS. RF Energy Harvesting for Wireless Devices. International Journal of Engineering Research and Development. 2015 Apr;11(4):39-52.

7. Kaiser KL. Electromagnetic shielding. Florida: CRC Press Book; 2005.

8. Jia Z, Lan D, Lin K, Qin M, Kou K, Wu G, Wu H. Progress in lowfrequency microwave absorbing materials. Journal of Materials Science: Materials in Electronics. 2018 Oct;29(20):17122-17136.

9. Micheli D, Apollo C, Pastore R, Marchetti M. X-Band microwave characterization of carbon-based nanocomposite material, absorption capability comparison and RAS design simulation. Composites Science and Technology. 2010 Feb;70(2):400-409.

10. Wang C, Murugadoss V, Kong J, He Z, Mai X, Shao Q, Chen Y, Guo L, Liu C, Angaiah S, et al. Overview of carbon nanostructures and nanocomposites for electromagnetic wave shielding. Carbon. 2018;140:696-733. 
11. Jenkins DR. Lockheed Martin F-117 Nighthawk. North Branch: Specialty Press; 1999.

12. Zhao H, Cheng Y, Lv H, Ji G, Du Y. A novel hierarchically porous magnetic carbon derived from biomass for strong lightweight microwave absorption. Carbon. 2019 Feb;142:245-253.

13. Liu Q, Zhang D, Fan T. Electromagnetic wave absorption properties of porous carbon/Co nanocomposites. Applied Physics Letters. 2008 Jul;93:013110.

14. Li YW, Song J, Wei JL, Zhou YB, Li G. Characteristic of porous carbon fiber and its microwave absorption as filler for composite. Applied Mechanics and Materials. 2014 Jul;577:48-52.

15. Chen CC. Transmission of Microwave Through Perforated Flat Plates of Finite Thickness. IEEE Transactions on Microwave Theory and Techniques. 1973;21(1):1-6.

16. Munk BA. Frequency selective surfaces: theory and design. New York: John Wiley \& Sons; 2000.

17. Singh D, Kumar A, Meena S, Agarwala V. Analysis of frequency selective surfaces for radar absorbing materials. Progress In Electromagnetics Research B. 2012 Jan;38(38):297-314.

18. Kingsley N, Guerci JR. Radar RF Circuit Design. New York: Artech House; 2016.

19. Shavit R. Radome Electromagnetic Theory and Design. New York: John Wiley \& Sons; 2018.

20. Narayan S, Sangeetha B, Rakesh MJ. Frequency Selective Surfaces-Based High Performance Microstrip Antenna. In: Narayan S, et al. Frequency Selective Surfaces based High Performance Microstrip Antenna. Singapore: Springer; 2016. p. 1-40.

21. Choi JH, Ahn J, Kim JB, Kim YC, Lee JY, Oh IK. An electroactive, tunable, and frequency selective surface utilizing highly stretchable dielectric elastomer actuators based on functionally antagonistic aperture control. Small. 2016;12(14):1840-1846.

22. Panwar R, Lee JR. Progress in frequency selective surface-based smart electromagnetic structures: A critical review. Aerospace Science and Technology. 2017 Mar;66:216-234.

23. Anwar R, Mao L, Ning H. Frequency Selective Surfaces: A Review. Applied Sciences. 2018;8(9):1689.
24. Li D, Li TW, Li EP, Zhang YJ. A 2.5-D Angularly Stable Frequency Selective Surface Using Via-Based Structure for 5G EMI Shielding. IEEE Transactions on Electromagnetic Compatibility. 2018;60(3):768-775.

25. Micheli D, Vricella A, Pastore R, Marchetti M. Synthesis and electromagnetic characterization of frequency selective radar absorbing materials using carbon nanopowders. Carbon. 2014;77:756-774.

26. Lee SE, Lee WJ, Oh KS, Kim CG. Broadband all fiber-reinforced composite radar absorbing structure integrated by inductive frequency selective carbon fiber fabric and carbon-nanotubeloaded glass fabrics. Carbon. 2016 Oct;107:564-572.

27. Inagaki M, Kang F, Toyoda M, Konno H. Advanced materials science and engineering of carbon. Oxford: ButterworthHeinemann; 2013.

28. Nicolson AM, Ross GF. Measurement of the Intrinsic Properties of Materials by Time-Domain Techniques. IEEE Transactions on Instrumentation and Measurement. 1970;19:377-382.

29. Vicente AN, Dip GM, Junqueira C. The step by step development of NRW method. In: SBMO/IEEE MTT-S International Microwave and Optoelectronics Conference (IMOC 2011). Natal: IEEE, 2011; p. 738-742.

30. Luukkonen O, Maslovski SI, Tretyakov SA. A Stepwise Nicolson-Ross-Weir-Based Material Parameter Extraction Method. IEEE Antennas and Wireless Propagation Letters. 2011 Dec;10:1295-1298.

31. Vassilev SV, Baxter D, Andersen LK, Vassileva CG. An overview of the composition and application of biomass ash. Part 1. Phase-mineral and chemical composition and classification. Fuel. 2013 Mar;105:19-39.

32. Debarros F, Lemaitre-Auger P, Menezes AVG, Siragusa R, Vuong TP, Tourtollet GEP, Fontgalland G. Characterization of frequency-selective surface spatial filters in a rectangular waveguide. International Journal of Microwave and Wireless Technologies. 2012 Feb;4(1):59-69.

33. Kshetrimayum RS, Zhu L. EBG design using FSS elements in rectangular waveguide. Applied Computational Electromagnetics Society Journal. 2006 Jul;21(2):149-154. 